CALCIUM DIFFUSION IN A MUGEARITE MELT

ABSTRACT

The diffusion coefficients of calcium are determined for a range of temperatures from 1230 ( $D=$ $\left.1.07 \times 10^{-7} \mathrm{~cm}^{2} / \mathrm{sec}\right)$ to $1423^{\circ} \mathrm{C}\left(\mathrm{D}=3.36 \times 10^{-7} \mathrm{~cm}^{2} / \mathrm{sec}\right)$ in a mugearite melt at atmospheric pressure. Diffusion is induced by establishing an initial concentration difference. The diffusion gradient is measured with the electron microprobe in conjunction with a statistical technique which eliminates the need for comparisons with standards, and hence affords a considerable saving in the time required for an analysis. The measured curve is evaluated using methods'assuming both composition dependent and constant diffusion coefficients. While the latter gives reasonably consistent results, the former is more appropriate as a composition dependence over the concentration range used is discernible. The activation energy obtained from the estimated coefficients, $29.5 \mathrm{kcal}$ per mole, is shown to be consistent with the classification of calcium diffusion as a $\mathrm{Ca}^{++}$cation controlled process. The application of mass transfer data to the modelling of diffusion controlled crystal growth in a cooling dike is outlined.

Gary A. Medford Dept. of Geological Sciences Master of Science 
Spine title

G.A. Medford

CALCIUM DIFFUSION IN A MUGEARITE

MELT 
.

\section{CALCIUM DIFFÚSION IN A MUGEARITE MELT}

\section{by}

\section{Gary A. Medford}

A thesis submitted to the Faculty of

Graduate Studies and Research in partial:

fulfilment of the requiremente for the degree of Master of Solenoe.

\section{Department of Geologioal Sciences,} McGill Univeraity, Montreal.

(C) Gary A. Medford 1971 
TABLE OF CONTENTS

INTRODUCTION

General . . . . . . . . . . . . . 1

Previous Work ...... . .. ... . . .. 2

EXPERIMENTAL PROCEDURE

Method of Diffusion .. ........ . . 4

Sample Preparation . . . . • - • •. 5

Analysis of the Starting Material . • • ..7

Apparatus . . . . . . . . . . . . $\because 11$

THEORY

Diffusion Equations . . . . . . . . . 12

Evaluation of the Diffusion Gradient . . 14

Measurement of the Diffusion Gradient : - 17

CALCULATIONS AND RESULTS

Example of Calculation : : ... • • • • 21

Computed Coeffioients and Activation Energy 24

DISCUSSION

29

ACKNOWLEDGEMENTS

34

REFERENCES 


\section{TABLES}

Table 1 .. Analyses of the Fused Mugearite, Base, and Spiked Material. . . . . . .. 9

Table $2 \ldots$ Iron and Alkall Analyses of Base Rook

Fused for Various Lengths, of Time at

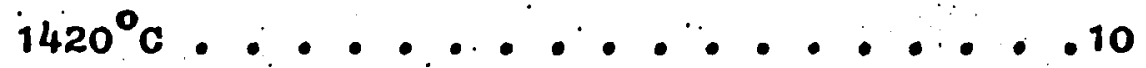

Table 3... Calculated Diffusion Coefficients. $\therefore . .26$

FIGURES

Figure 1 ... An example of a diffusion curve obtained from a sample run at $1344^{\circ} \mathrm{C} . . .20$

Figure 2 . a- Analysis assuming a constant diffusion coefficient

b- A plot of dc/dx versus $x$ using data from the curve of figure 1. ....23

Figure $3 \because \log _{10}{ }^{D}$ versus $1 / T m$ plot of the data obtained in this and another study of calciun diffusion. . . . . . . 
0

\section{CALCIUM DIFFUSION IN A MUGEARITE}

\section{MELT}

(a) 


\begin{abstract}
.
The diffusion coefficienta of calcium are determined for a range of temperatures from 1230 ( $D=$ $\left.1.07 \times 10^{-7} \mathrm{~cm}^{2} / 800\right)$ to $1423^{\circ} \mathrm{C}\left(D=3.36 \times 10^{-7} \mathrm{~cm}^{2} / \mathrm{sec}\right)$ in a mugearite melt at atmospherio pressure. Diffusion is Induced by establishing an initial concentration difference. The diffusion gradient is measured with the electron microprobe In confunction with a statidital technique which eliminates the need for comparisons with standards, and hence affords a considerable saving in the time required for an analysis. The measured curve is evaluated using methods assuming both composttion dependent and constant diffusion coefficients. While the latter gives reasonably consistent resulto, the former is more appropriate.as a composition dependence, over the concentration range used is discernible. The activation energy obtained from the estimated coeffioients, $29.5 \mathrm{kcal}$ per mole, Is shown to be consistent with the classification of calcium diffusion as a $\mathrm{Ca}^{++}$cation controlled process.

The application of mass transfer data to the modeling of diffusion controlled orystal growth in a cooling dike is outined.
\end{abstract}




\section{INTRODUCTION}

General

Shaw (1963) pointed out the need for work on

the kinetio properties of natural eystems, Inoluding information on viscosity and diffusion, in order to better understand the mechanism of intrusion and crystallization of magmatio bodies. Since then an extensive investigation of viscosity has been effeoted (Shaw ot al. 1968, Shaw 1969. Bottinga and Weill 1970), but diffusion coefficients for olements in natural melts have not as yet been determined, no doubt largely a result of the absence of an expedient analytical method to deteot the individual concentration gradients in a multicomponent system: The avallability of the electron microprobe, however, has prompted the author to examine it as a device for measuring diffusion gradients. The theory and mothod of analysis are presented in connection with the measurement of calcium diffugion in a mugiearite melt, for a range of temperatures. The activation energy of the process is thereby determined. 
Previoug Work

The geological literature includes several publications concerned with diffusion which are mostiy qualitative discussions of its role and importance in geological processes. Interest was aroused in the late nineteenth century by proponents of the soret effect (for a summary see Wahl 1946, and Eitel 1954) but its importance remained questionable. The ensuing controversy prompted Bowen (1921) to undertake the first experimental work in geology from which he obtained estimates of the diffusion rates of the elements of diopside and plagioclase. From his experiments he concluded that diffusion caused by the soret effeot is too slow to account for any appreciable concentration gradients before complete solidification of mogt igneous bodies.

In 1946, Wahl suggested that differentiation by thermodiffusion (Soret effect plus convection) is important and cited several examples including Mount Johnson with its pulasicite-essexite asgooiation (see also Philpotts 1968). Barth (1952) oupported his views and argued in favour of the process, although no kinetic data was avaliable to conclusively prove or disprove its importance. Recent1y, Oppenhelm (1968), to test the possIble effeots of eleotrical currents within the earth, has 
a

performed experiments in which differentiation is achieved by electrolysis of a molten basalt, and some Soviet workers have revived interest in the Soret effect (Schienmann 1969) and are apparently working on diffusion, a1though nothing has been published to the author's knowledge. 
Method of Diffusion

The method utilized was similar to that used by Bowen (1921), that is, diffusion vertically against gravity caused by an initial concentration gradient. The starting material or base rock was spiked by adding calcium oxide in sufficient quantity to allow detection by the electron microprobe. At the same time, the difference was kept as small as possible to minimize composition dependence of the diffusion coefficient. The diffusion couple was held in a platinum crucible with a $.508 \mathrm{~cm}$ outside diameter and $.0381 \mathrm{~cm}$ wa11s, formed by crimping one end of a tube shut and welding it. The crucible was about $2.3 \mathrm{~cm}$ long, thus allowing each part of the diffusion couple to occupy at least $1 \mathrm{~cm}$ of constant diameter cross-section. The wall thickness was greater than that absolutely necessary but served to help equalize any temperature gradients along the sample length. The calcium oxide spiked material, being denser than the base material, was placed at the bottom of the crucible to prevent convection. 
Sample Preparation

The starting material was a fine-grained dike rock which was crushed and fused in a $50 \mathrm{ml}$ alumina crucible in air for three hours at $1350^{\circ} \mathrm{C}$ to allow: for the degassing of water and other volatiles. Preliminary investigation revealed minor contamination and reaction with the crucible over a distance of much less than $0.1 \mathrm{~cm}$. This contaminated material was discarded and the remainder crushed to $100 \mathrm{mesh}$ and ground in a mechanical agate mortar for forty minutes. Half of this material was weighed into convenient $1.6 \mathrm{gm} 10 \mathrm{ts}$ to which $0.046 \mathrm{gm}$ of calcium oxide was added, and these portions were then ground for an additional forty minutes." The other half was retained as the base material. Both spiked and base samples were then fused in platinum for four more hours at $3420^{\circ} \mathrm{C}$. The former was reground for another forty : minutes and the latter crushed to 50 mesh or less.

A small quantity of spiked powder was added to the crucibie and fused long enough to allow bubbles to escape (about 10 minutes). The process was repeated many times until the crucible was half filled. This procedure was necessary to prevent the formation of large bubbles stretching right across the crucible as they would never rise to the surface. The filling was done at $1420^{\circ} \mathrm{C}$ as the melt was sufficiently inviscid at 
this temperature to allow rapid degassing. The charge was then left for about twenty hours to allow homogenization after which it was quickly withdrawn from the furnace. A tool steel rod was then forced down the crucible to flatten the meniscus. Material which had coated the upper half of the cruclble was then removed by reaming with a flat ended drill rod and a fine silica carbide abrasive. This also formed a flat interface on the glass surface.

The unspiked material had to be added quickly to prevent unwanted diffusion. At the same time; bubble formation had to be avoided. This was achieved by filling the remainder of the crucible with the relatively coarse base material (except at the interface where a fine dusting of powder was used to form a flat surface) and fusing for $15-20$ seconds at $1420^{\circ} \mathrm{C}$. Because of compaction upon melting, this had to be repeated two or three times, but the aggregate loading time formed an insignificant portion of the total run times and the correction required was insignificant. 
Analysis of the Starting Material

The rock was collected from a dike on the eastern side of Mount Royal, Quebec, Canada and the fused material has the bulk and normative compositions given in Table "I". These correspond closely to the mugearites described by Muir and Tilley (1961). The analysis recalculated to one hundred percent is used as the base rock analysis and the composition of the spiked rock is also shown. The rock is texturally . similar to photomicrograph $B$ in Muir and Tilley (1961) ard consists of about 60 percent feldspar (.1mm), 25 percent green altered pyroxene or amphibole (:1mm) sometimes preserved as aligned oxide minerals, 10 percent calcite occuring as small patches throughout the matrix, and 5 percent oxides. Scattered phenocrysts of plagioclase (.5mm) with replaced cores of muscovite and minor scapolite are also present.

To check for iron loss to the crucible, and alkali loss which might occur during prolonged heating, small samples of the base rock were heated for various lengths of time in open platinum crucibles at $1420^{\circ} \mathrm{C}$. The results (Table II) indicate insignificant loss compared with the analytical variation of the analyses. The oxidation state of iron was not controlled and the 


\begin{abstract}
Feo content was found to have changed from 5.44 to 1.97 percent in a sample fused for 20 hours at $1420^{\circ} \mathrm{C}$.
\end{abstract}

(4) 


\section{TABLE I}

ANALYSES OF THE FUSED MUGEARITE; BASE; AND SPIKED MATERIAL

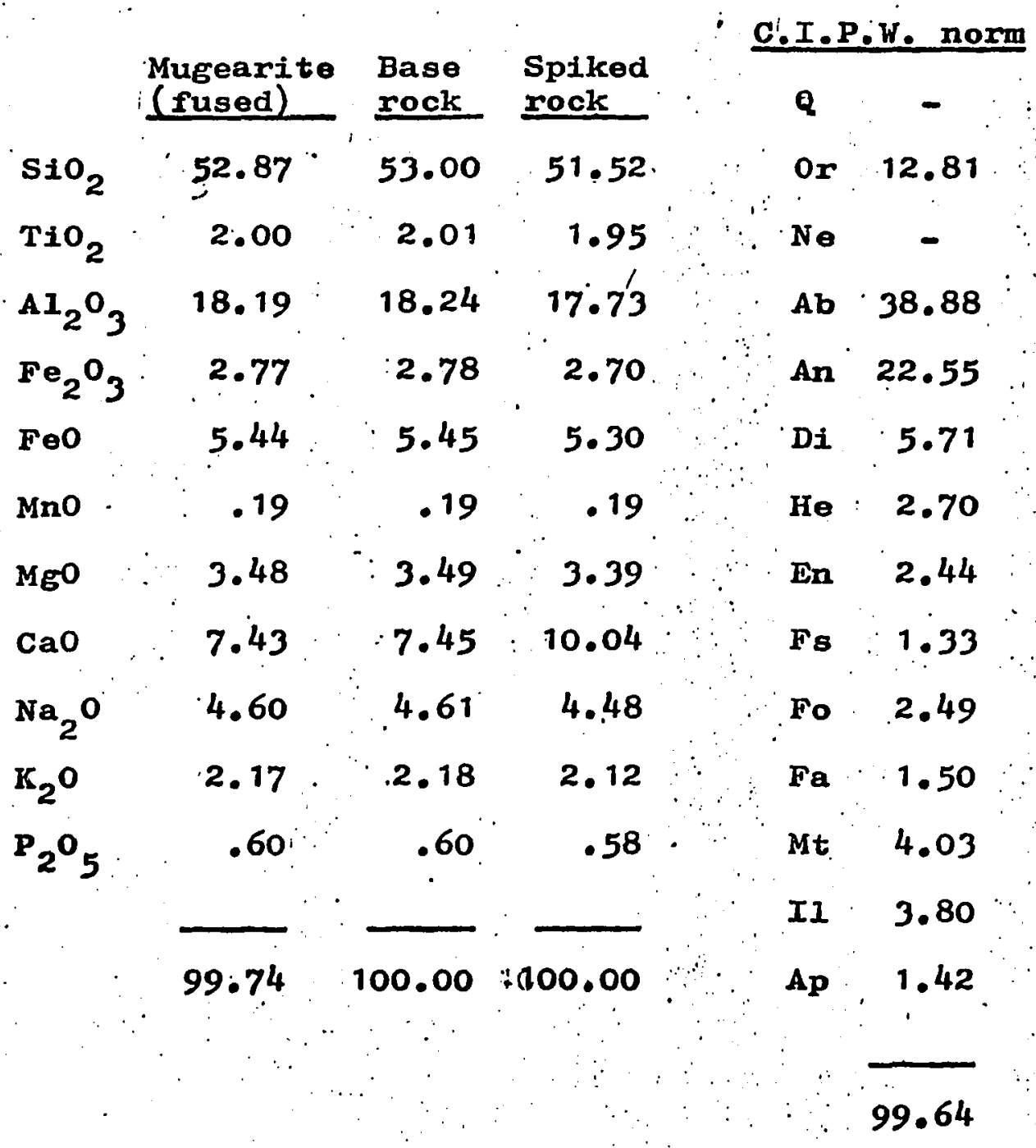




\section{TABLE II}

IRON AND ALKALI ANALYSES OF BASE ROCK FUSED FOR VARIOUS LENGTHS OF TIME AT $1420^{\circ} \mathrm{C}$

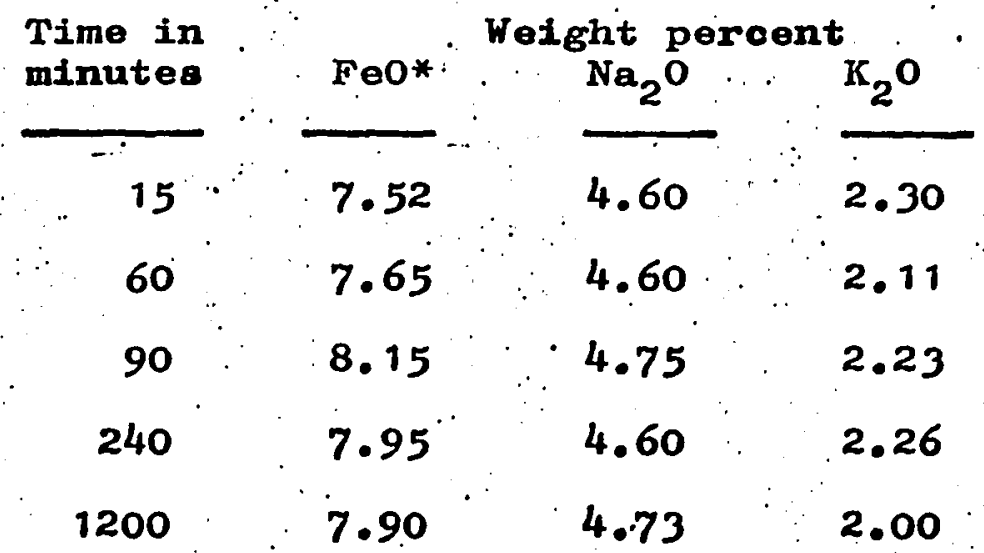

* Total iron expresied as Feo 
Apparatus.

A vertical Pt60-Rh40-wound furnace was used with an internal alumina tube slightly wider than the crucible so that $a \mathrm{Pt}$ and $\mathrm{P} \pm 87-\mathrm{Rh} 13$ thermocouple could be placed at the midsection of the charge.

The' temperature gradient was determined before each run at the run temperature and was always 1088 than $1.5^{\circ} \mathrm{C}$ over the length of the sample. The temperature was monitored continuously using a digital voltmeter and was kept at $\pm 2.0^{\circ} \mathrm{C}$ for the duration of the experiment by adjusting a variac which controlled the external power

' supply. The run temperature: was attained within about two minutes of lowering the crucible into position by preheating the furnace 20 or $30^{\circ} \mathrm{C}$ above the run temperature. 


\section{THEOFY}

Diffusion Equations

Given an n-component aystem in which each species,i, is diffusing because of $n$ concentration

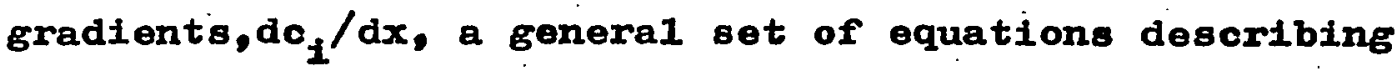
the flux, $J_{i}$, of each species is

[1]

$$
J_{i}=D_{11} d c_{1} / d x+\ldots+D_{i n} d c_{n} / d x .
$$

where the fluxes are considered linear functions of the concentration gradients (Onsager 1945-46). The units of $c_{i}$ can be expressed in many ways (Bird et al. 1960,pp.496) and for convenience $x$-ray counts per $\mathrm{cm}^{3}$ are used. The number of counts was verified in these experiments to be a linear function of the weight percent calcium oxide, and making. the common assumption of negligible volume change on mixing, this unit can thus be considered proportionall to grams calcium oxide per unit volume. -The $D_{i i}\left(\mathrm{~cm}^{2}\right.$ per sec) are the main diffusion coefficients of each species $i$ and the $D_{i j}, i \neq j$, are the cross-diffusion coefficients accounting for the effect of concentration gradient $j$ on the $f l u x J_{i}$. These equations have been dealt with for n-component systems where the coefficients are not composition dependent (Fujita and Gostings 1956, Baldwin et al, 1955), but formulation for $n>$ in a 
manner which permits, them to be applied to experimental data is difficult and requires extreme precision in measurement. In this work the composition differences, apart from calcium, were so small (see Table I) that no other gradients could be detected. For most practical purposes it is sufficient to determine the diagonal coefficients;" Dii, separately and this is the procedure used here. The equations describing the process (i.e. the change in concentration at any time at any position) assume a simple form analagous to those describing heat conduction (Carslaw and Jaeger 1959)

$$
\partial c(x, t) / \partial t=\partial^{2} D C(x, t) / \partial x^{2}
$$

where $c(x, t)$ is the concentration at position, $x$, at time, $t$, and $D$ is assumed dependent on concentration and hence on $x_{\text {. If }} \mathrm{D}$ is not concentration dependent then [2] becomes

$$
\partial c(x, t) / \partial t=D \partial^{2} c(x, t) / \partial x^{2}
$$

Equation [3] gives a satisfactory description of the system if the concentration difference between the couples is kept small. Should any dependence exist then an areraged value of $D$ is obtained for the specified composition range. 
Evaluation of the Diffusion Gradient

The solution to [3] for some time, $t=T$,

assuming an initial concentration difference, $C_{0}$;

is (Carslaw añd Jaeger 1959)

[4]

$$
c(x, T)=\left(c_{0} / 2\right)(1-\operatorname{erf}(x / 2 \sqrt{D T}))
$$

which can be rewritten

[5]

$$
\begin{aligned}
-\left(2 c(x, T) / c_{0}\right)+1 & =\operatorname{erf}(x / 2 \sqrt{D T}) \\
& =2 / \sqrt{\pi} \int_{0}^{x / 2 \sqrt{D T}} e^{-\lambda^{2}} d \lambda \\
& =2 / \sqrt{\pi} \int_{0}^{x} e^{-\lambda^{2} / 4 D T} d \lambda
\end{aligned}
$$

Thus by plotting observed values of the left side of [5] on normal probability paper (Bennet and Franklin 1954) one can obtain an estimate of the second moment about the mean, 8 , and noting that

$$
\text { . } s=2 D T
$$

calculate $D$, since the run time $T$ is known.

Equation [2] can be utilized to analyse a given concentration gradient employing Boltzmann's Integration technique (Jost 1960). Defining a variable,b, such that 
[7]

$$
b=x / \sqrt{t}
$$

then

[7]

$d x=\sqrt{t} d b$

and

[7]. $a x=b / 2 \sqrt{t} d t$

Slibstituting the above into[2] gives

$$
\mathrm{bdc} / 2=\mathrm{d}(\mathrm{Ddc} / \mathrm{db})
$$

which can be integrated and rearranged into

$$
1 / 2 \int_{0}^{c} b d c=D d c / d b
$$

and

[10]

$$
D=(1 / 2)(d b / d c) \int_{a}^{c} b d c
$$

respectively. At the end of a run of duration $T$ [7] becomes $b=x / \sqrt{T}$, so $[10]$ is now

$$
D=(1 / 2 T)(d x / d c) \int_{0}^{c(x)} x d c
$$

By determining $d x / d c$ graphically at the concentra- 
tion $c(x)$ of interest, as well as the integral on the right, D can be evaluated at that concentration. The plane $x=0$ is not necessarily the original interfaoe but is determined such that

$$
\int_{0}^{c(x=0)} x d c=c(x=0) \int_{0}^{c_{0}}-x d c
$$

since conservation of mass requires

$$
\int_{0}^{C_{0}} x d c=0
$$

The above two methods of evaluation assume that diffusion has taken place in an infinitely extended system. Practically speaking there should be no signifi$\because \because$ cant change at the ends of the sample. This was ensured by comparison with standards of the same composition differefice, and by verifying that the curve had leveled out a few mm before the endpoints. The composition extremes were then fixed quite accurately by averaging the points in the level parts of the curve. 
Measurement of the Diffusion Gradient

The sample was ground along 1 ts length to half its thickness and polished to a degreo suitable for microprobe analysis. Ten-second counts were taken on a central line along the length of the sample at $0.05 \mathrm{~cm}$, and in some cases $0.025 \mathrm{~cm}$; intervals.

To evaluate the curve, one is interested in obtaining the composition of points relative to each other. If the microprobe was completely stable (no drift, etc.) one could simply analyse each position in tum, with as many ten-second counts as required to gain the desired statistical precision. This is not the case, however, and so the following procedure, utilizing a blocking and randomization scheme (Cochran and Cox 1957), was used to obtain the required internal consistency. A block was taken to be composed of one ten-second.count at each of.the positions along the length of the sample. The order of the positions analjsed was then randomized within each block, and as many blocks as desired were completed. The analysis of each block was performed as quickly as possible. Thus any drift components are incorporated in the variance of the estimate of each positicn, the precision of the analysis then being [14]

$$
\tau(x) \pm t .025, p-1 \hat{6} / \sqrt{p}
$$


where $\bar{c}(x)$ is the mean of the readings at position $x, \hat{\sigma}$ $i s$ an estimate of the standard deviation and $p$ is the number of readings (blocks). Up to 32 readings were taken. at each position but $12-14$ were ultimately found to be sufficient. In general, the precision required and hence the value selected for $p$ would depend on the overall difference in counts between the spiked sample and the base material. In these experiments the range was about 300 counts and the precision obtained with pet at 14 was plus or minus about 20 counts for 95 percent confidence limits, that is, plus or minus: 6.7 percent of the total range.:A curve obtained using 14 analyses per position is shown in Fig.t.

The validity of using the absolute number of counts as a measure of the concentration is explained as follows. It was determined for calcium that

$\begin{aligned} & \text { [15] Composition of sample } \\ & \text { in weight percent CaO }\end{aligned}=\left[\begin{array}{l}\text { Counts on sample-background } 1 \\ \text { Counts on standard-background } 2\end{array}\right]$ $X\left[\begin{array}{l}\text { Composition of standard } \\ \text { in weight percent } \mathrm{CaO}\end{array}\right]$

which can be rewritten

[15] Counts on sample = Composition of sample $\mathrm{x}\left[\frac{\text { Counts on standard-background } 2}{\text { Composition of standard }}\right]$ +background 1: 
Thus, all other things remaining constant, the number of counts is direotly proportional to the composition of the eample.:

It is ovident from [15] that if a eignificant average change In "Counts on standard" occurs between blocks (because, say, of a change in the operating characteristics with time) it is not correct to compute the mean of the readings of the same position in the different blocks as each would obviously contribute a disproportionate weight, and [14] would no longer be valid. Such a change is reflected in a variation of the mean from one block to the next and can readily be corrected by discarding blocks which are significantly different from the others or by multiplying each reading in these blocks by a suitable correction factor.

The procedure outlined above eliminates the need for constant comparisons with a standard to obtain the composition of each position. Assuming that an equal number of measurements would have to be made on both standard and sample to gain a desired precision, this method sares half the time required for the analysio. 
20

Figure 1 An example of the curve obtained from the mun at $1344^{\circ} \mathrm{C}$ of duration 43200 seconds. The line $x=0$ is obtrained according to equation [12] and serves as the abscissa for the integration in equation [1] . The shaded portion is the area integrated. 


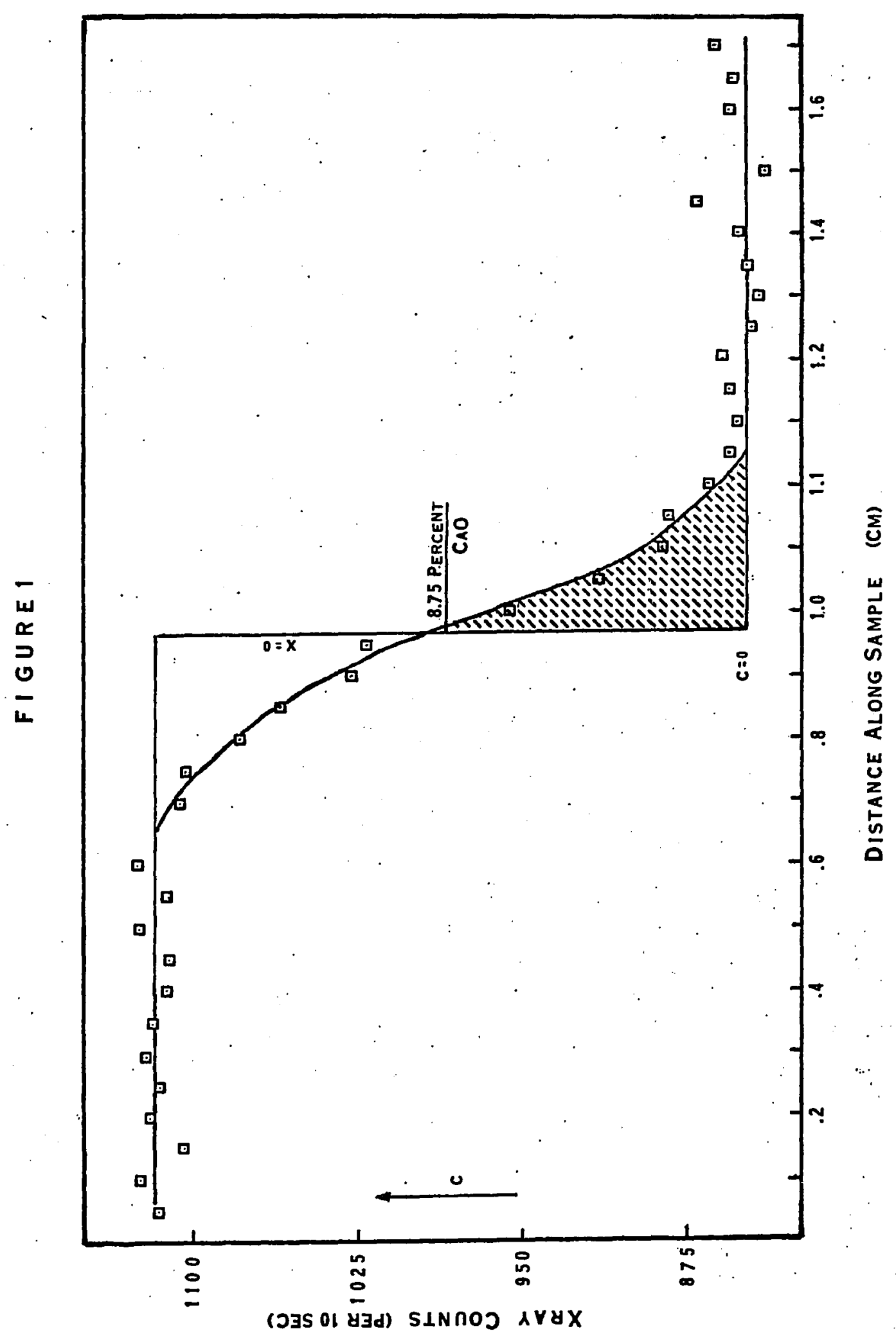


CALCULATIONS AND RESULTS

Example of Calculation

Concentrations (counts per $\mathrm{cm}^{3}$ ) taken from the curve of Fig.1. are plotted on normal probability paper (FIg.2a) according to the method involving equations $[3,5]$. The mun time is $T=43200$ seconds. The value of $x .18 \cdot 137 \mathrm{om}$, and using [6]

$$
\text { since } \theta=x^{2}
$$

$$
\text { one has } D=s / 2 T=2.18 \times 10^{-7} \mathrm{~cm}^{2} / 800
$$

It can be seen that the points depart from a otraight Iine, which should not occur if $D$ is constant throughout the concentration range. This corresponds to a skewed bell curve when values of $d c / d x$ taken from the graph are plotted against $x$ (Fig.2b), whereas it can be rerified that the same differential of [4] is symmetrical. The analysis of the same run as above using equations $[2,11]$ is for a composition midway botween the spiked and base rock composition. Here (see Fig.1)

$$
\therefore \int_{0}^{c=8.75 \% \mathrm{cao}} x \mathrm{dc}=14.3 \mathrm{count-cm}
$$


22

$d x / d c=0.00135 \mathrm{om} /$ count

$$
1 / 2 T=1 / 86400 / 800
$$

and 80 by this method

$$
D_{C=8.75 \% C a O}=2.24 \times 10^{-7} \mathrm{om}^{2} / 800
$$


Figure 2 a-An example of the evaluation of the diffusion coefficient using equation 5. The departure of the points from the straight line expected under the assumptions of the model is evident. b-The departure in $2 a$ is mirrored as a skewed be11 curve when $d c / d x$ is plotted against $x$. 


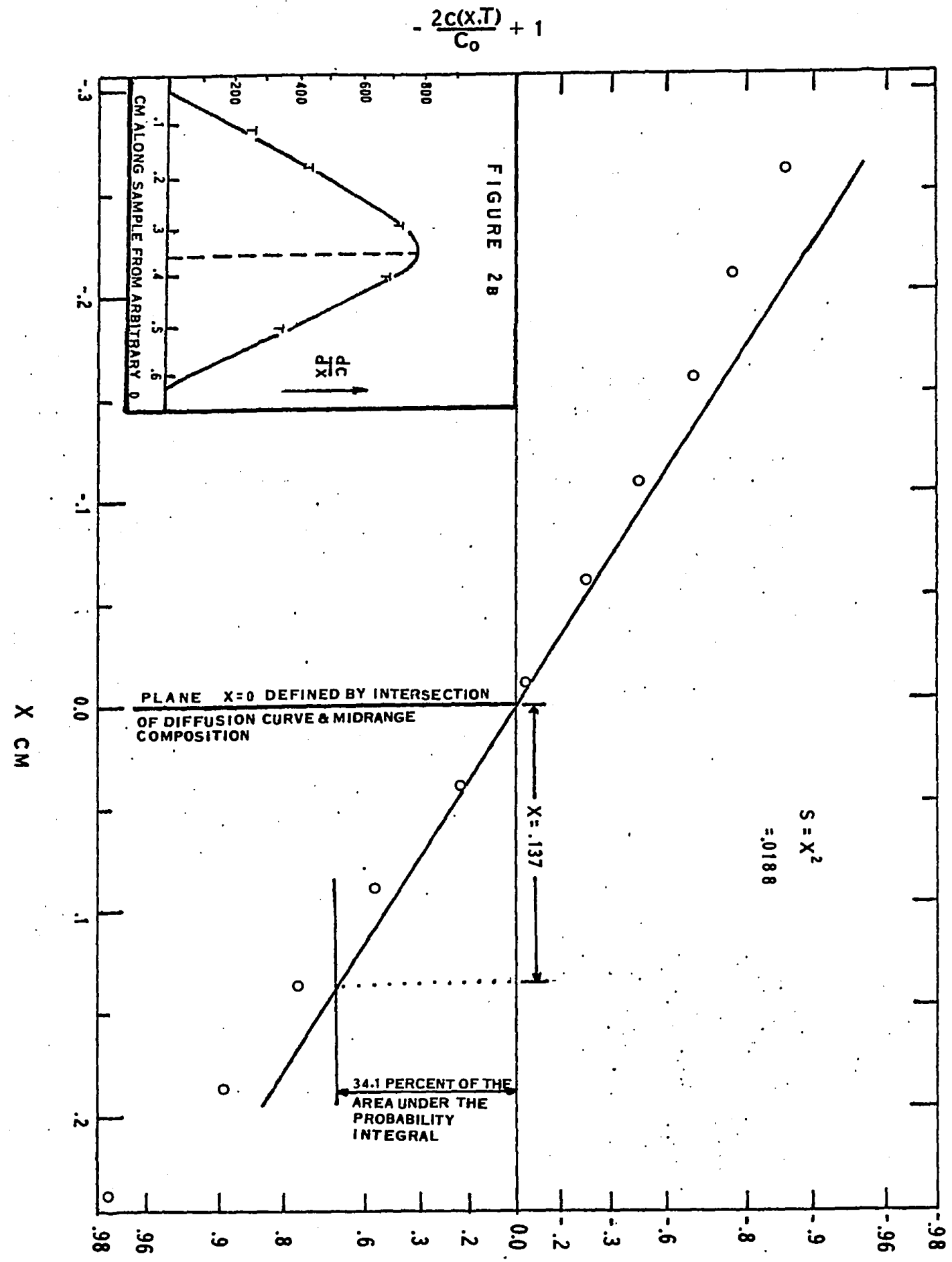

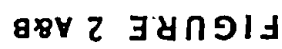




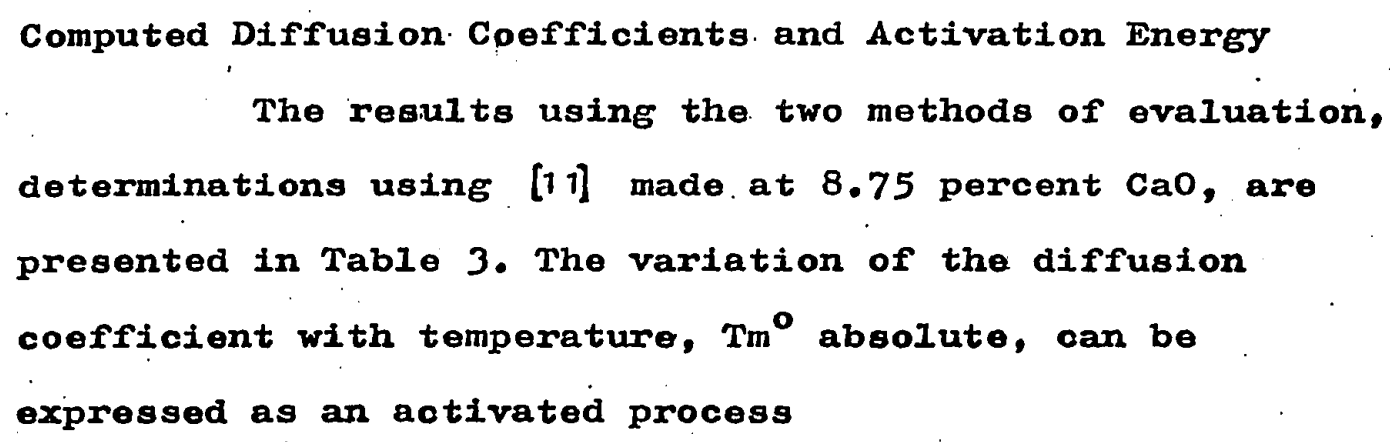

where $Q$ is the activation energy of diffusion, $R$ the gas constant, and $A$ a pre-exponential constant. Hence changing [16] to

$$
\log _{10} \mathrm{D}=-\mathrm{Q} /(2 \cdot 303 \mathrm{RTm})+\log _{10} A
$$

one can estimate $Q$ from the slope of the line of a $\log _{10} D$ versus $1 / \mathrm{Tm}$ plot (Fig.3). The value of $Q$ obtained by least squares is $29.5 \mathrm{kcal}$ per mole, and the pre-exponential A is $2.04 \times 10^{-3} \mathrm{~cm}^{2} / \mathrm{sec}$.

The errors involved in using the method of equation [1] are extensively discussed by Rhines and MehI (1938). The chief source of error in these experiments is that a statistical variation in the points requires a subjective fit to be made to obtain the diffusion curre. Thus interpretational differences, especially near the endpoints, cause some variation in the integrated areas. The slope 
$\mathrm{dx} / \mathrm{dc}$, on the other hand, can be estimated quite accurately especially at the midrange compositions. In view of the above, the calculated diffusion coeffioients are considered to be accurate to plus or minus 15 percent. From Table III, the estimates using the constant coefficient method [5] are scattered od both sides of the other estimates, and except for one case, are within the limits of error given for the latter. One would expect equation [5] to give results consistently near the midrange composition values when the composition dependence is not too severe, as is the case in these experiments. These estimates, however, are considered to be less reliable than the others because of the extension of the probability paper near the edges (Fig.2a). This gives undue weight to the ends of the diffusion curve - precisely the parts which are most difficult to estimate. The exact slope of the fitted line"is hence extremely. hard to evaluate. Thus the method using equation [1]];is preferred. In the Iimiting case of no composition dependence, equal results would be obtained at all positions (all concentrations) on the curve.

Because of discrepancies in preparation, the CaO content in some spiked samples was found to be .1 or .2 percent lower than quoted in Table $I$. Thls was readily compensated for using [11], and was judged to have no significant effeot on estimates utilizing [5]. 


\section{CALCULATED DIFFUSION COEFFICIENTS}

$-\mathrm{cm}^{2} / \mathrm{sec}-\therefore$

Temperature ${ }^{\circ} \mathrm{C}$

1230

$1265 \cdot 5$

1300

1344

$1389: 5$

1423
Composition Dependent $D$ Method

$\begin{array}{r}1.07 \\ 1.49 \\ 1.63 \\ 2.24 \\ 2.87 \\ 3.36 \\ \times 10^{-7} \\ \hline\end{array}$

Constant D Method

$\begin{array}{r}1.93 \\ 1.56 \\ 1.47 \\ 2.18 \\ 2.93 \\ 2.95 \\ \times 10^{-7} \\ \hline\end{array}$

Based on column 1:

Activation Energy $Q=29.5 \mathrm{kcal} / \mathrm{mole}$

Pre-exponential . $A=2.04 \times 10^{-3} \mathrm{~cm}^{2} / \mathrm{sec}$ 
Figure 3 Diffusion coefficients obtained by McCallum and Barrett(1952) for olage containing 37.5, 32.5, and 27.5 percent $\mathrm{CaO}$ are given by Iines 1,2 , and 3 respectively: Each contained 10 percent $\mathrm{Al}_{2} \mathrm{O}_{3} ;$ the rest being $\mathrm{SiO}_{2} \cdot$ Line 4 is derived from the mugearite in this invertigation, evaluated at 8.75 percent CaO. 
FIGURE 3

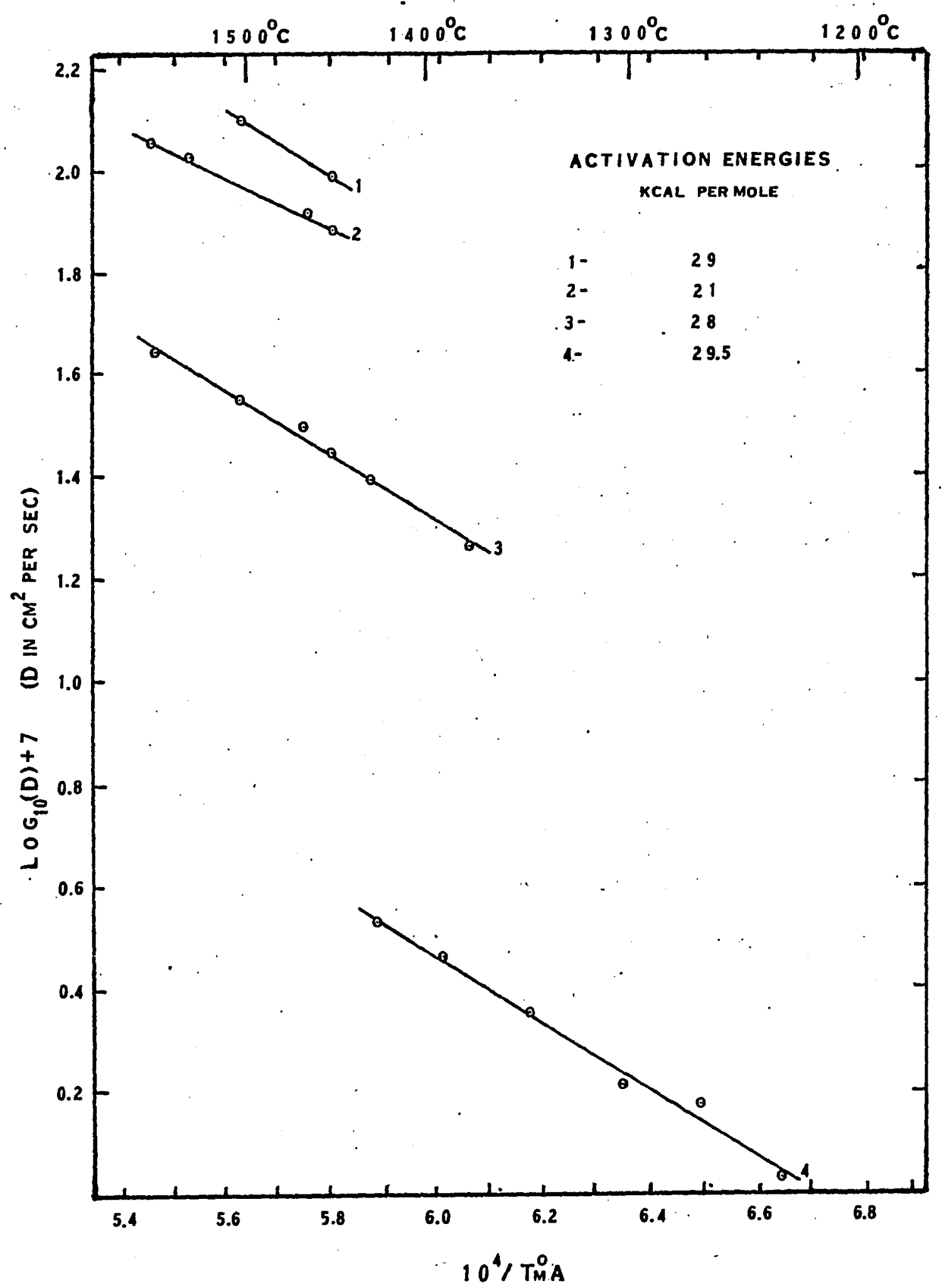




\section{DISCUSSION}

Calcium diffusion in CaO-AI $\mathrm{O}_{3}-\mathrm{SiO}_{2}$ aystems of various proportions was followed by McCallum and Barrett ( 7952$)$, and their results are plotted in Fig.3.. The activation energy at 27.5 percent CaO was determined to be $28 \mathrm{kcal}$ per mole which is remarkably close to that in the present work, although their coefficients are about one order of magnitude higher. A decrease in the diffusion rates is evident for decreasing CaO content, but this observation may be fortuitous as the mugearite melt is compositionaliy quite different from the slags. Towers et al: (1953) using radioactive calcium determined its coefficients in a slag of 40 percent Cao, 20 percent $\mathrm{AI}_{2} \mathrm{O}_{3}$, and 40 percent $\mathrm{SiO}_{2}$. The data showed considerable spread and gave estimates of $3.3 \times 10^{-7}$ and $1.3 \times 10^{-6} \mathrm{~cm}^{2} / \mathrm{sec}$ at 1350 and $1450^{\circ} \mathrm{C}$. The activation energy was calculated to be 70 kcal per mole plus or minus 20 kcal per mole.

To maintain electrical neutrality, either cations plus anions must migrate together (anion controlled diffusion), or the cations must migrate separately ( cation controlled diffusion) with some other sort of charge compensating mechanism being operative. In the former case, the activation energy might be expeoted to be oloeer to 
that required for viscous flow, whioh is an anion controlled process. This activation energy was determined by McCallum and Barrett to be about $46 \mathrm{kcal}$ and hence they proposed that the rate determining step was the jump of a cation from one equilibrium position to another. Their explanation of the charge compensation. is not clear and they, themselves, point out that the mechanism is hard to visualize. The results of this work are consistent with this division into anion and cation controlled processes. Eulex and Winkler (1957) demonstrated that melts with $(S i+A I) / 0^{*}$ ratios between .40 and .47 consistently display viscosity activation energies of 50 to 60 kcal per mole, and hence one would expect this rock, $(S i+A I) / O=.430$, to have a value somewhere in that range. Consequently the 29.5 kcal per mole estimate obtained here would tend to support a $\mathrm{Ca}^{++}$cation controlled process. The variation in concentration of the other elements due to the calcium diffusion was unfortunately impossible to record. Presumably it is through crossdiffusion, because of activity gradients of all the species, that the chemical potential of each component in the melt is equalized, and electrical neutrality preserved. As far as the present analytical procedure Is concerned, one can only hope to evaluate the diffusion $\because \because$ rates of all the elements separately. This approach should, $\because \cdots \cdot \cdot$ *in atomic percent 
nevertheless, provide a useful phenomenological description of the system at hand, and provide sufficient information, in conjunction with thermal and momentum transport properties; to attempt quantitative modelling of cooling magmas. Bird et al. (1960) give various examples of mass transfer models utilized in engineering analysis, often using simplified approximations where the mathematics . becomes intractable. As an illustration, the following description of the growth of a crystal in a cooling dike, using the activated process description of $D$ as a function of temperature, equation [16], is presented. For simplicity consider an idealized plane crystal of unit area which grows by accretion on each face. Suppose; further, that the growth process is diffusion controlled and the crystal nucleates at time $t_{0}$ and grows from $t_{0}$ to $t_{f}$, during which time the melt is supersaturated with respect to the crystal by an amount $\Delta c_{0}$; where $\Delta c_{0}$ is conveniently expressed in terms of the rate controlling element. Then the change in $\Delta c_{0}$ away from the face a distance $x$ after an elapsed time is described by

$$
\partial c / \partial t=D(t) \partial^{2} c / \partial x^{2}
$$

If the substitution

[18].

$$
d z=D(t) d t
$$


is made in [17] then an analytical solution can be obtained (Carslaw.and Jaeger 1959), that 1s,

$$
c(x, z)=2 \Delta c_{0} \operatorname{erf}(x / 2 \sqrt{z})
$$

(for x positive)

assuming growth on two faces, and that the crystals do not compete for material. The mass of the crystal, $M$, (expressed in terms of the rate controlling element) Is obtained by integration of 2Ac 1088 [19]

$$
\text { [20] }{ }_{j} \quad{ }_{M=2}^{i}\left(c_{0}-c(x, z)\right) d x .
$$

The abovemay be evaluated if $z$ can be procured. Integrating. [18] over the time of interest, one has

$$
z=\int_{0}^{t} f(t) d t
$$

and since it has.boen shown that

$$
D(t)=A e^{-Q / R T m}(t, y)
$$

(where $\mathrm{Tm}$ is now a function of time and a specified position, $y$, in the dike) [21] can be numerically evaluatod If a ouitable temperature history is avallable. In this case, Ignoxing latent heat, one has for a dike of width 2a (Carelaw and Jaegex 1959) 


$$
\text { [22] } \operatorname{Tm}(y, t)=\left(\operatorname{Tm}^{0} / 2\right)\{\operatorname{erf}[(a-y) / 2 \sqrt{\lambda t}]-\operatorname{erf}[(a+y) / 2 \sqrt{2 x t}]\}
$$

where $x$ is the thermal diffusivity and $\mathrm{Tm}^{\circ}$ is the initial temperature. Thus the size of the crystal is ultimately given by equation [20]. To have such a model duplicate the textural variation in a dike would obviously require the incorporation of a suitable nucleation model and much refinement, and it is included merely to outline. how phenomenological measurements of diffusion could be employed. For simplicity, only equations for which analytical solutions are available were used, but the sophistication of the model can be increased many-fold by utilizing appropriate numerical techniques. 


\section{ACKNOWLEDGEMENTS}

The author would like to thank Dr. A.R. Philpotts for guidance during the course of this work. Thanks are also extended to Dr. W.H. MacLean for assistance and discussion regarding the use of the electron microprobe, and to Mr. W. Doig for technical advice.

Funds were made available by Dr. A.R. Philpotts through National Research Council grant No. A-2668. 
REFERENCES

Baldwin,R.L.,Dunlop,P.J ., and Gostings,L.J.1955.Interacting flows in liquid diffusion: equations for the evaluation of the diffusion doefficients from moments of the refractive index gradient curves. J.Amer.Chem.Soc.,77,Pp.52355238.

: Barth,T.F.W.1952. The differentiation of a composite aplite from the Pribilof Islands, Alaska. Bowen vol., Amer. J.Sci.,pp.27-36.

Bennett,C:A.and Franklin,N.L.1954. Statistical analysis in chemistry and the chemical industry. John Wiley and Sons. New York.

Bird,R.B.,Stewart,W.E. and Lightfoot,E.N.1960. Transport phenomena. John. Wiley and Sons. New York.

Bottinga, Y. and Weill,D.F.1970. Viscosity of anhydrous silicate melts.'Trans. Amer.Geophys.Un, 51, pp. 439.

Bowen,N.L. 1921. Diffusion in silicate melts. J.Geo1.,29, pp. 295-317.

Carslaw,H.S. and Jaeger,J.C.1959. Conduction of heat in solids.2nd. edition. Oxford University Press. 
Cochran,W.G.and Cox,G.M.1957. ExperimentaI Desiens. John Wiley and Sons. New York.

Eitel,W.1954. The physical chemistry of the silicates. University of Chicago Press.

Euler,R. and Winkler,H.G.F.1957. Uber die viskositaten von gesteins- und silikatschemlzen, Glastech. Ber., 30, pp.325-332.

Fujita,H.and Gostings,L.J.1956. An exact solution of the equations for free diffusion in three-component systems with interacting flows, and its use in. the evaluation of the diffusion coefficient. Amer.Chem.Soc.J .,78,pp.1099-1106.

Jost,W.1960. Diffusion in solids, Iiquids, gases. Revised edition. Academic Press, New York. McCallum,N.and Barrett,L.R.1952. Some aspects of the corrosion of refractories. Trans.Brit.Ceram.Soc., 51, pp. 523-544.

Muir,I.D.and Tilley,C.E.196i. Mugearites and their place in alkali igneous rock series. J.Geol.,69, pp. 186-203.

Onsager,L.1945-46. Theories and problems of 1iquid diffusion. Ann.N.Y. Acad.Sci, ,46,pp.241-265.

Oppenheim,M.J.1968. On the electrolysis of molten basalt. . Mineral.Mag.,36,pp.1104-1122.

Philpotts,A.R.1968. Igneous structures and mechanism of 
emplacement: of Mount Johnson, a Monteregian intrusion, Quebec, Can.J.Earth Sci.,5,pp.11311137.

Rhines,E.N. and Mehl,R.F.1938. Rates of diffusion in the $\therefore$ alpha solid solutions of copper. Trans.A.I.M.E., $128, \mathrm{pp} \cdot 185-222$.

Scheinmann,Yu.M.1969. Discussion of the paper "The origin of basaltic and nephelenitic magmas in the earth's mantle" by D.H. Green. Tectonophysics,7,pp.423426.

Shaw,H.R. 1963. Obsidian- $\mathrm{H}_{2} \mathrm{O}$ viscosities at 1000 and 2000 bars in the temperature range $700^{\circ} \mathrm{C}$ to $900^{\circ} \mathrm{C}$. J.Geophys.Res. . 68, pp.6337-6343. - Wright, T.L.,Peck,D.L. and Okamura,R. 1968. The viscosity of basaltic magma:an analysis of field measurements in Makaopuhi lava lake, Hawaii. Amer.J.Sci., 266,pp.225-264. 1969. Rheology of basalt in the melting range. $J$. Petrol., 10,pp.510-535.

Towers,H.,Paris,M.,Chipman,J.1953. Diffusion of calcium ion in liquid slag. Trans.A.I.M.E., 197,pp.14557458. 
Wahl,W. 1946. Thermal diffusion-convection as a cause of magmatic differentiation.I. Amer.J.Sci.,44, pp. 417-441. 